\title{
Polar ionospheric responses to solar wind IMF changes
}

\author{
Y. Zhang ${ }^{1}$, D. J. McEwen ${ }^{1}$, W. Guo ${ }^{1}$, P. C. Anderson ${ }^{2}$ \\ ${ }^{1}$ Department of Physics, University of Saskatchewan, Saskatoon, S7N 5E2 Canada \\ e-mail: zhang@dansas.usask.ca \\ ${ }^{2}$ Aerospace Corporation, Los Angeles, USA
}

Received: 25 August 1999 / Revised: 7 February 2000 / Accepted: 7 March 2000

\begin{abstract}
Auroral and airglow emissions over Eureka $\left(89^{\circ}\right.$ CGM) during the 1997-98 winter show striking variations in relation to solar wind IMF changes. The period January 19 to 22, 1998, was chosen for detailed study, as the IMF was particularly strong and variable. During most of the period, $B_{z}$ was northward and polar arcs were observed. Several overpasses by DMSP satellites during the four day period provided a clear picture of the particle precipitation producing the polar arcs. The spectral character of these events indicated excitation by electrons of average energy 300 to $500 \mathrm{eV}$. Only occasionally were electrons of average energy up to $\sim 1 \mathrm{keV}$ observed and these appeared transitory from the ground optical data. It is noted that polar arcs appear after sudden changes in IMF $B_{y}$, suggesting IMF control over arc initiation. When $B_{y}$ is positive there is arc motion from dawn to dusk, while $B_{y}$ is negative the motion is consistently dusk to dawn. F-region (antisunward) convections were monitored through the period from $630.0 \mathrm{~nm}$ emissions. The convection speed was low $(100-150 \mathrm{~m} / \mathrm{s})$ when $B_{z}$ was northward but increased to $500 \mathrm{~m} / \mathrm{s}$ after $B_{z}$ turned southward on January 20.
\end{abstract}

Key words: Atmospheric composition and structure (airglow and aurora) - Ionosphere (particle precipitation) - Magnetospheric Physics (polar cap phenomena)

\section{Introduction}

The polar ionosphere is very sensitive to changes in the solar wind, especially the interplanetary magnetic field (IMF). When the IMF $B_{z}$ is southward, F-layer patches often appear in the polar cap with strong anti-sunward

Correspondence to: Y. Zhang convection (McEwen et al., 1995; McEwen and Harris, 1995, 1996). The convection is considered to occur mainly in a two-cell pattern (Heelis, 1984). Weak electron precipitation may occur as "polar rain" (100$200 \mathrm{eV}$ ). No auroral emissions are observed, except on rare occasions during major magnetic storms through poleward expansion of the auroral oval (McEwen and Huang, 1995).

When the IMF $B_{z}$ is northward, structured electron precipitation often occurs in the polar region, resulting in polar auroral arcs, at very high geomagnetic latitudes $\left(>80^{\circ}\right)$ that extend some distance in a sun-earth direction (Davis, 1960; Carlson, 1990; Oznovich and McEwen, 1994; Huang et al., 1994). Some of these arcs are very bright and extend across the polar region from the dayside to the nightside of the auroral oval to form a pattern of Greek letter "theta" (Frank et al., 1982). Some arcs are spatially unstable with a dawn-dusk speed as high as $500 \mathrm{~m} / \mathrm{s}$ (Rich et al., 1990; Valladares and Carlson, 1991). Optical observations from ground stations (such as Eureka, or Qaanaac, Greenland) and satellites (Viking, POLAR) provide respectively detailed and global-scale information on such polar arcs. Particle detection from satellites (such as DMSP) can give detailed fluxes and energy distributions of the particles exciting these polar arcs. Such information may provide clues as to the source of polar arcs, a question now still under debate.

Using particle data from ISIS-2 Murphree et al. (1983) reported that the average energy of electrons causing polar arcs was in the range of 300 to $600 \mathrm{eV}$. Plasma parameters of the near magnetotail have been established using data from IMP 6 at distances around $30 R_{E}$ (Fairfield, 1987). The author showed that there are statistically two components of electrons in the near magnetotail lobes. One has a typical energy around $200 \mathrm{eV}$, another is around $2 \mathrm{keV}$. By using ISEE-3 measurements, Baker et al. (1997) demonstrated the relatively frequent occurrence of low-energy (50$500 \mathrm{eV}$ ) electron flux enhancements within the distant magnetotail lobes. These electrons were found to be 
'bidirectional' in the sense that intensities were highest parallel (and antiparallel) to the lobe magnetic field lines. Similar plasma electron features have also been found using the Low Energy Particle sensor system onboard the GEOTAIL spacecraft (Baker et al., 1997). Gosling et al. (1996) used measurements made by the Fast Plasma Experiment on ISEE 2 and reported observations of accelerated magnetosheath plasma within the lobe magnetopause current layer. They found that lobe magnetopause reconnection events occurred at times of large local field shears at the magnetopause; these large field shears were associated primarily with large IMF $x$ and $y$ components rather than with the $z$ component. Fairfield et al. (1996) reported that the size of the deep magnetotail was reduced to $12 R_{E}$ after the magnetosphere was in northward IMF $B_{z}$ for $12 \mathrm{~h}$. This indicates well-compressed magnetotail lobes and is consistent with smaller auroral oval following a longtime northward IMF. These studies have shown that magnetosheath plasma can be accelerated and enter the magnetotail lobes via the magnetopause. A question to be addressed here is whether such plasmas can be the source of the polar arcs.

\section{Observations of polar ares}

\subsection{Comparisons between optical and particle data}

In this study, high-resolution optical data from Eureka station are studied in relation to simultaneous DMSP particle data, through a 4-day period in January, 1998 when the IMF was large and variable. In addition, Fabry Perot Interferometer (FPI) data from Eureka are used to monitor neutral F-region winds in relation to IMF changes. Figure 1 shows a sketch of the auroral oval and location of the Eureka Observatory at $89^{\circ}$ Corrected Geomagnetic (CGM) latitude near the north magnetic pole. This location is ideal for observations of polar arcs as it is well away from the auroral oval. A Meridian Scanning Photometer (MSP) and an All-Sky Camera (ASC) at Eureka are able to detect auroral emissions over the central polar region down to $80^{\circ}$ CGM. The MSP scanning direction is set in a duskdawn direction and thus it automatically scans across the sun-aligned polar arcs and can record their motions and intensity changes.

Figure 2 is a plot of the IMF $B_{x}, B_{y}, B_{z}$, solar wind density $(N)$ and solar wind speed $\left(V_{x}\right)$ in the Earth-Sun direction over the 4-day period, January 19-22, 1998. The IMF $B_{z}$ was positive for most of that period, but went negative for about $10 \mathrm{~h}$ on January 20 .

The orientation of IMF $B_{z}$ is seen to determine the nature of particle precipitation in the polar region. When $B_{z}$ is negative there is often weak unstructured electron precipitation, as illustrated in Fig. 3. This is a plot of total electron energy flux and mean electron energy of precipitating electrons observed by the DMSP F13 satellite in a polar pass around 1611 UT on January 20, 1998, when the IMF $B_{z}$ was $-8 \mathrm{nT}$. The DMSP pass traversed the polar region in a dusk-dawn direction up

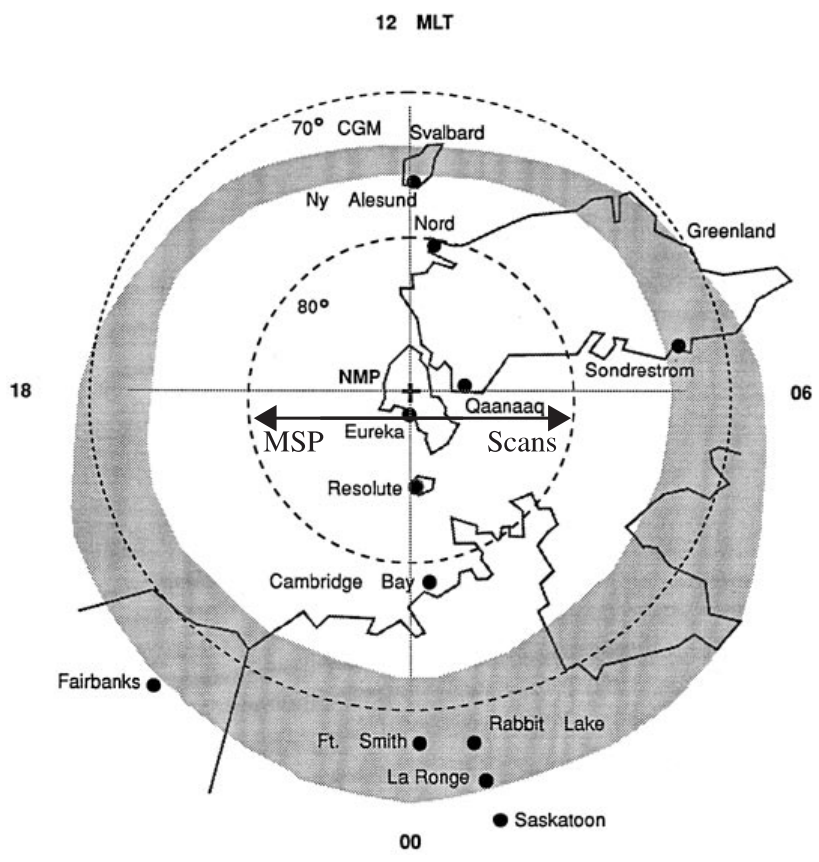

Fig. 1. A sketch of the auroral oval and location of Eureka $\left(89^{\circ}\right.$ CGM). The north magnetic pole $(N M P)$ is at the centre

to $88.9^{\circ} \mathrm{CGM}$. The polar boundaries of the auroral oval are identified at approximately $72^{\circ}$ on the dusk side and $79^{\circ}$ on the dawn side, as shown by the arrows in Fig. 3 . The electron energy flux is less than $10^{-3} \mathrm{ergs} /\left(\mathrm{cm}^{2} \mathrm{~s} \mathrm{sr}\right)$ with an average electron energy about $150 \mathrm{eV}$ presumably due to direct precipitation of solar wind halo electrons (about $100 \mathrm{eV}$ ) and/or solar wind electrons accelerated by the bow shock potential difference $(\sim 100 \mathrm{~V})$.

During most of the other three days, the IMF $B_{z}$ was northward and the polar region had structured electron precipitation which was sufficient to produce observable auroral arcs. We will look at three example periods for which both optical and particle data were available.

2.1.1 January 19, 1442 UT. The DMSP F13 satellite crossed overhead (at $88.1^{\circ} \mathrm{CGM}$ ) at 1450 UT on January 19,1998 . The IMF $B_{z}$ had just switched to $+10 \mathrm{nT}$ prior to this pass, as seen in Fig. 2. Figure 4 is a plot of electron energy flux and mean energy recorded by the F13 satellite from 1442 to 1458 UT. It clearly shows three narrow regions of electron precipitation at high latitude within the polar cap, whose dusk and dawn boundaries at about $82^{\circ}$ are indicated by two arrows. The latter two precipitations were within the Eureka field-of-view. The energy fluxes were 0.8 and $0.3 \mathrm{ergs} /\left(\mathrm{cm}^{2} \mathrm{~s} \mathrm{sr}\right)$, respectively. The corresponding average energies were around 400 and $500 \mathrm{eV}$. Figure 5 is a plot of the electron differential energy flux between 1450:00 and 1450:40 UT (top panel) and between 1451 and 1452 UT (lower panel) showing detailed spectra of the precipitating electrons. The two well-isolated electron precipitation events (around 1450:20 and 1451:35 UT) show inverted V structures with peak energies up to $500 \mathrm{eV}$. 


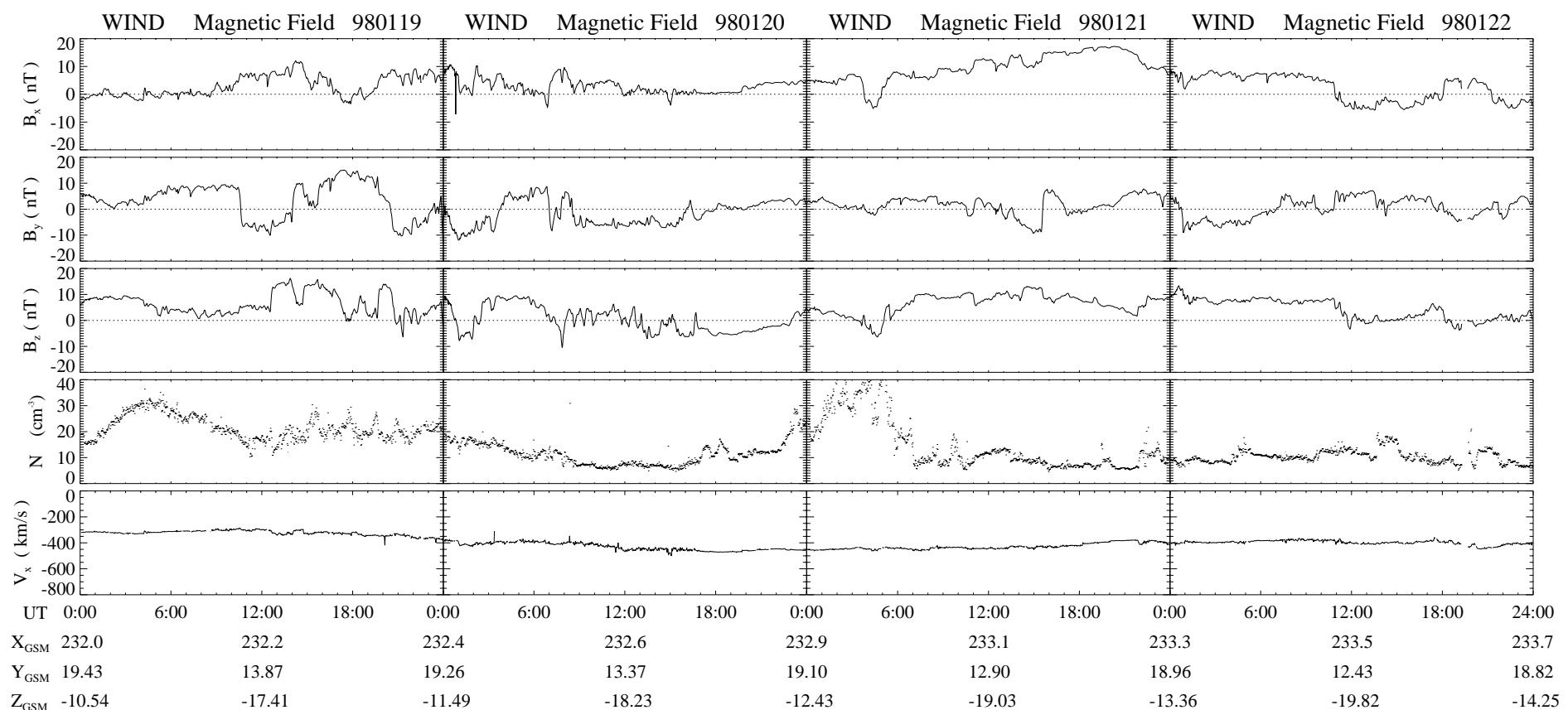

Fig. 2. Plots of IMF $B_{x}, B_{y}, B_{z}$, solar wind density $(N)$ and $x$-component $\left(V_{x}\right)$ of the solar wind speed from January 19 to 22,1998
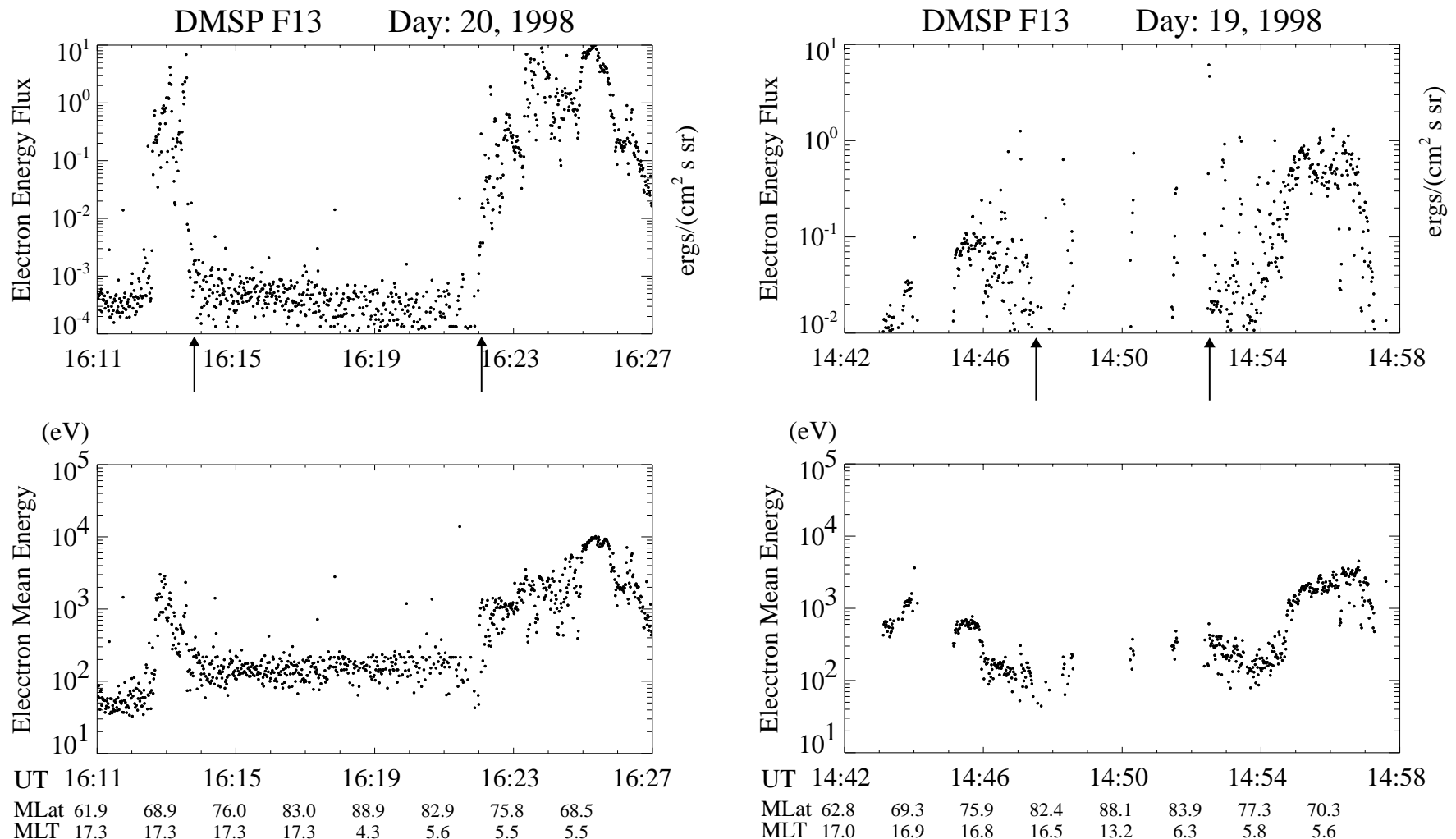

Fig. 3. A plot of DMSP F13 total electron energy flux in ergs $/\left(\mathrm{cm}^{2} \mathrm{~s} \mathrm{sr}\right)$ (top panel) and electron mean energy in $\mathrm{eV}$ (bottom panel) from 1611 to 1627 UT on January 20, 1998. The IMF $B_{z}$ is southward during the period. The dusk and dawn polar edges of the auroral oval are shown by arrows

Figure 6 shows the MSP scans along a dusk-to-dawn meridian, for three channels $(427.8,630.0$ and 557.7 $\mathrm{nm})$ from 1445 to $1500 \mathrm{UT}$. The MSP stack plots

Fig. 4. Similar to Fig. 3, but from 1442 to 1458 UT on January 19, 1998. The polar cap boundaries are identified by two arrows

clearly show that there are two major arcs (between 1450 and 1452 UT), one near the zenith on the dusk side, one near the horizon on the dawn side. The arc near zenith is due to the electron precipitation around 1450:20 UT seen in the DMSP pass (Fig. 5). The 630.0 and $557.7 \mathrm{~nm}$ intensities of the arc are 200 and $100 \mathrm{R}$ 
respectively at 1450:20 UT. The arc on the dawn side corresponds to the second region of electron precipitation. Its 630.0 and $557.7 \mathrm{~nm}$ intensities are 350 and $100 \mathrm{R}$ respectively. The $630.0 / 557.7 \mathrm{~nm}$ intensity ratios for both arcs are well above 1, consistent with the observation of low energy electron precipitation. That ratio remains high throughout the 15 min period shown

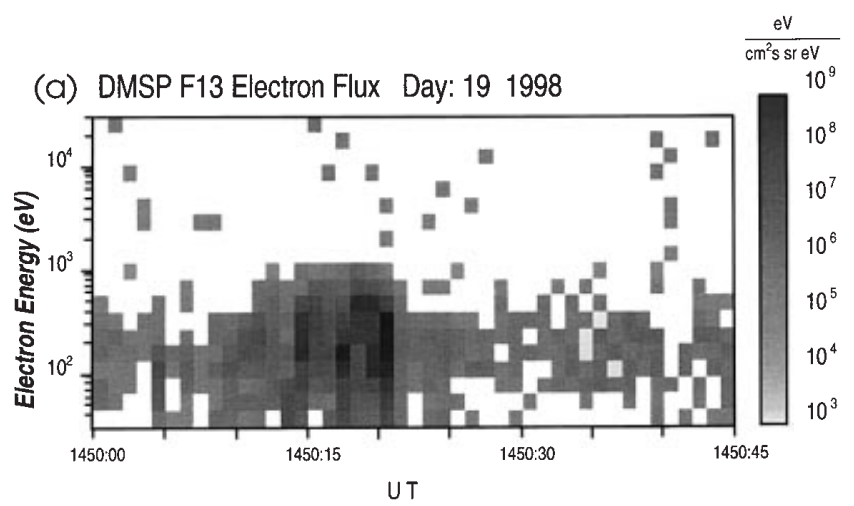

(b) DMSP F13 Electron Flux Day: 191998

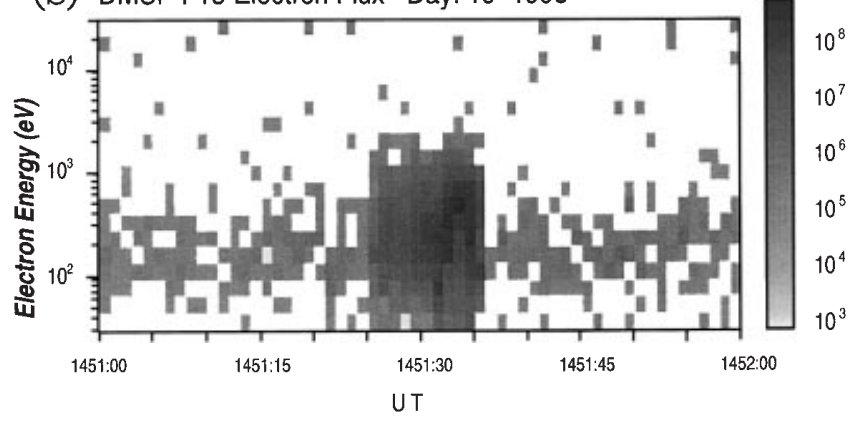

Fig. 5a, b. DMSP F13 differential electron energy flux a from 1450:00 to $1450: 40$ UT and b from 1451 to 1452 UT on January 19, 1998 in Fig. 6, except for brief periods when the $557.7 \mathrm{~nm}$ emission increases.

2.1.2 January 21, 1607 UT. The IMF $B_{z}$ was strongly positive for most of January 21, 1998 (see Fig. 2). Polar arcs were observed continuously from 0900 to 2400 UT through that day. Figure 7 shows the successive MSP scans from 1600 to 1615 UT. The DMSP satellite crossed the central polar region near the Eureka duskdawn meridian around 1607 UT. Figure 8 shows the electron energy flux and mean electron energy obtained from the satellite particle data. The dusk and dawn crossings of the auroral oval show about $0.2 \mathrm{ergs} /\left(\mathrm{cm}^{2} \mathrm{~s} \mathrm{sr}\right)$ fluxes of precipitating electrons of mean energy of 1-3 keV. The dusk and dawn polar boundaries of the auroral oval, as indicated by the highest latitude of continuous electron precipitation, are shown by arrows at $82^{\circ}$ and $79^{\circ}$ respectively. The polar region is seen to be nearly full of structured electron precipitation. Of note are events marked A, B, C, and D, with energy fluxes of $1-3 \mathrm{ergs} /\left(\mathrm{cm}^{2} \mathrm{~s} \mathrm{sr}\right)$. The mean energies of those precipitation events are 500, 600, 400 and $300 \mathrm{eV}$ respectively. There were small fluxes of ions of a few $\mathrm{keV}$ associated with the electron fluxes in events B to D, but no detectable ion flux in event A. All of these precipitations are well above the threshold for producing visual arcs and they can be identified in the $630.0 \mathrm{~nm}$ scans of Fig. 7 at 1607 UT (arc A duskward of zenith and $\operatorname{arcs} \mathrm{B}, \mathrm{C}$, and $\mathrm{D}$ dawnward of zenith). The arc intensities, better followed in the $557.7 \mathrm{~nm}$ scans, are quite variable. The optical spatial resolution of offzenith arcs is degraded relative to the in situ particle measurements of Fig. 8.

Figure 9a shows the differential energy flux recorded from 1606:50 to $1607: 40$ UT. It shows more clearly the structured precipitation of events A and B in Fig. 8 and the resulting arcs near zenith in Fig. 7. Event A produces the narrow arc seen in Fig. 7 some $10-15 \mathrm{~km}$ across.

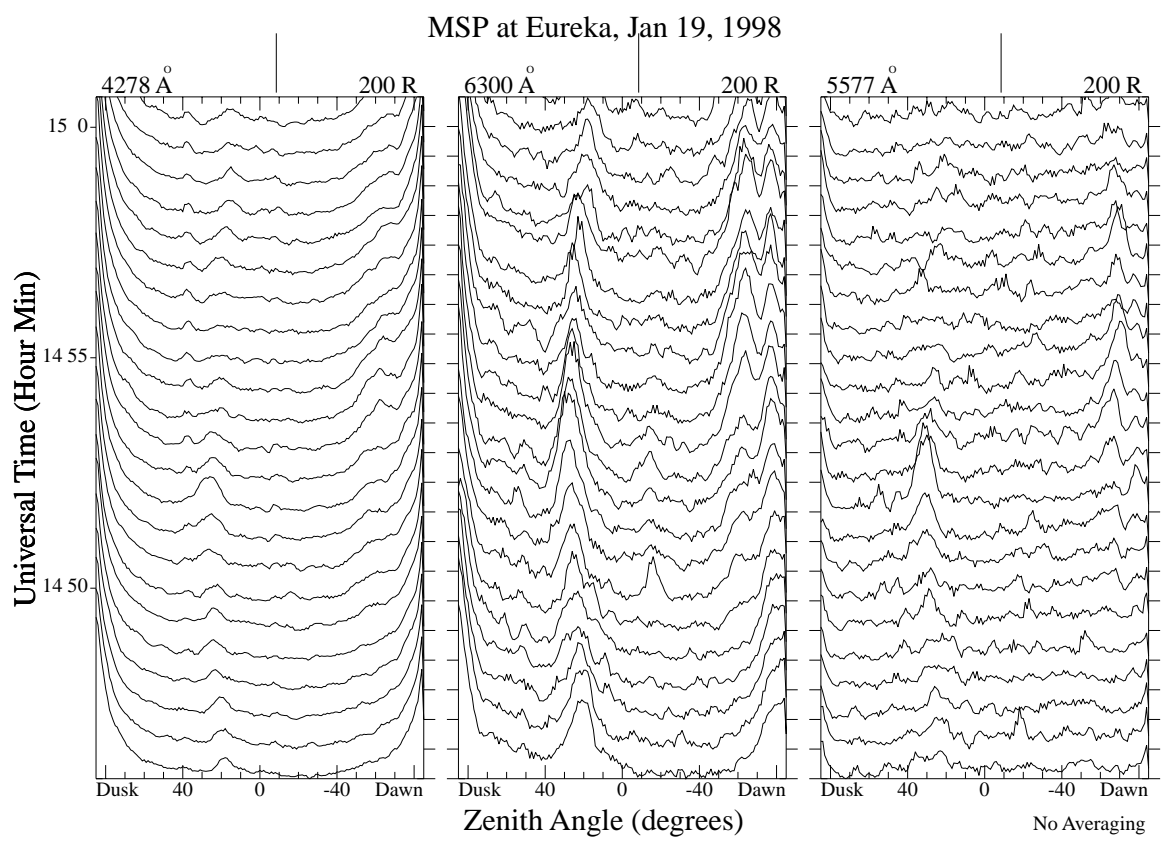

Fig. 6. Plots of Eureka MSP scans showing auroral intensities of $428 \mathrm{~nm}, 630.0 \mathrm{~nm}$ and $557.7 \mathrm{~nm}$ emissions along the dusk-dawn meridian over Eureka from 1445 to 1500 UT on January 19, 1998. The bars above each graph correspond to $200 \mathrm{R}$ 
MSP at Eureka, Jan 21, 1998
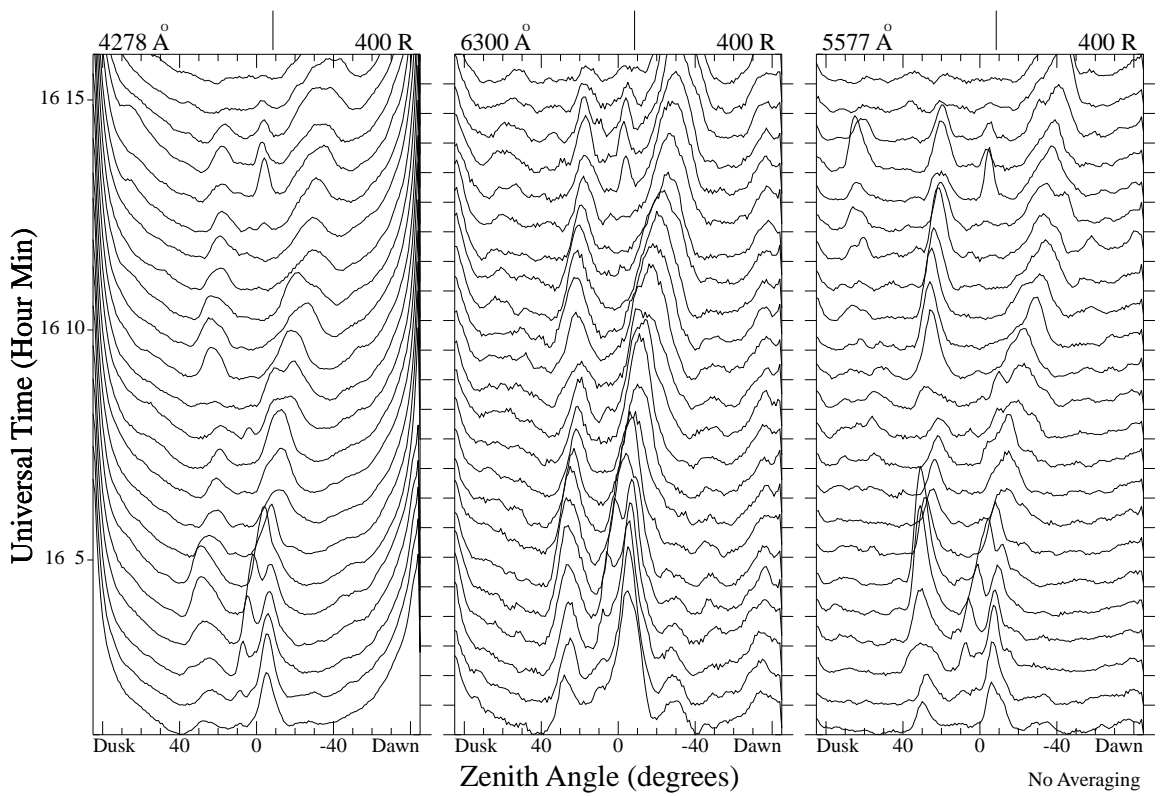

Fig. 7. Plots of Eureka MSP scans similar to Fig. 6, but from 1600 to 1616 UT on January 21, 1998
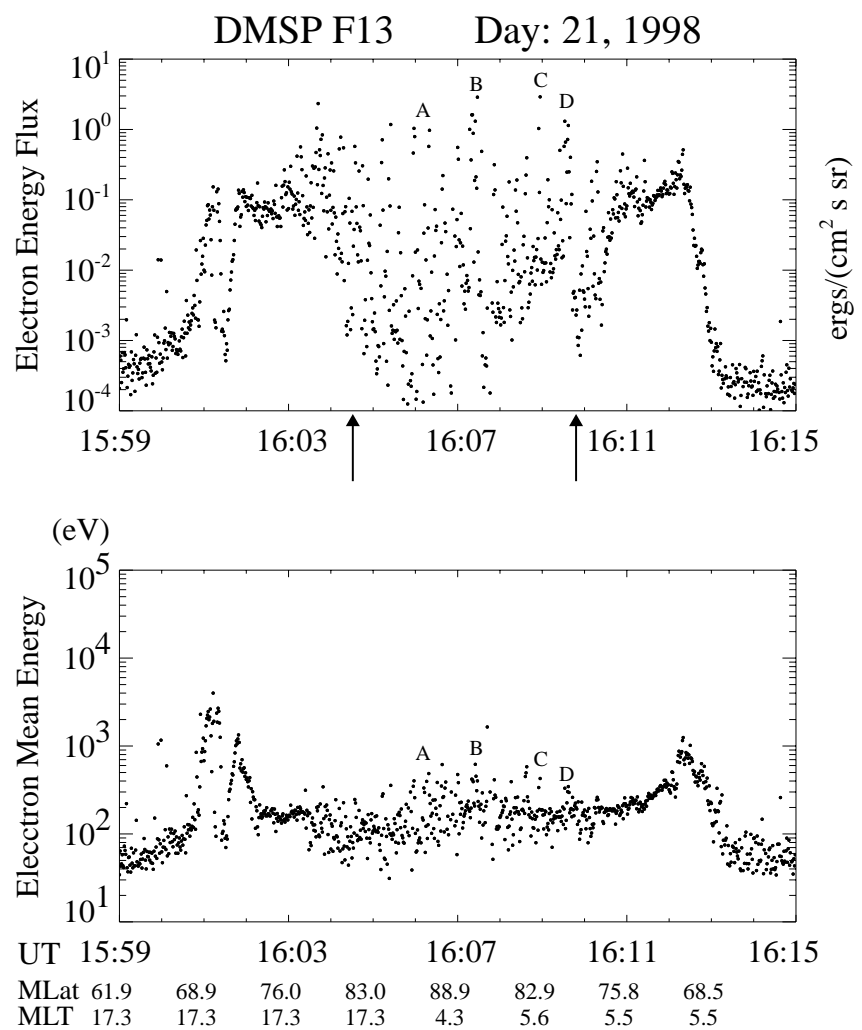

Fig. 8. DMSP F13 total electron energy flux and electron mean energy from 1559 to 1615 UT on January 21, 1998. Arrows mark the dusk and dawn boundaries of the polar cap

That arc, at $30^{\circ}$ zenith angle on the dusk side persists through the 15-min period shown but there are two periods (around 1604 and $1611 \mathrm{UT}$ ) when the $557.7 \mathrm{~nm}$ emission is substantially increased. At 1607 UT, the time of DMSP crossing, the $630.0 \mathrm{~nm}$ emission is dominant as expected from the $300 \mathrm{eV}$ average energy of electron precipitation. Event B consists of the two separated

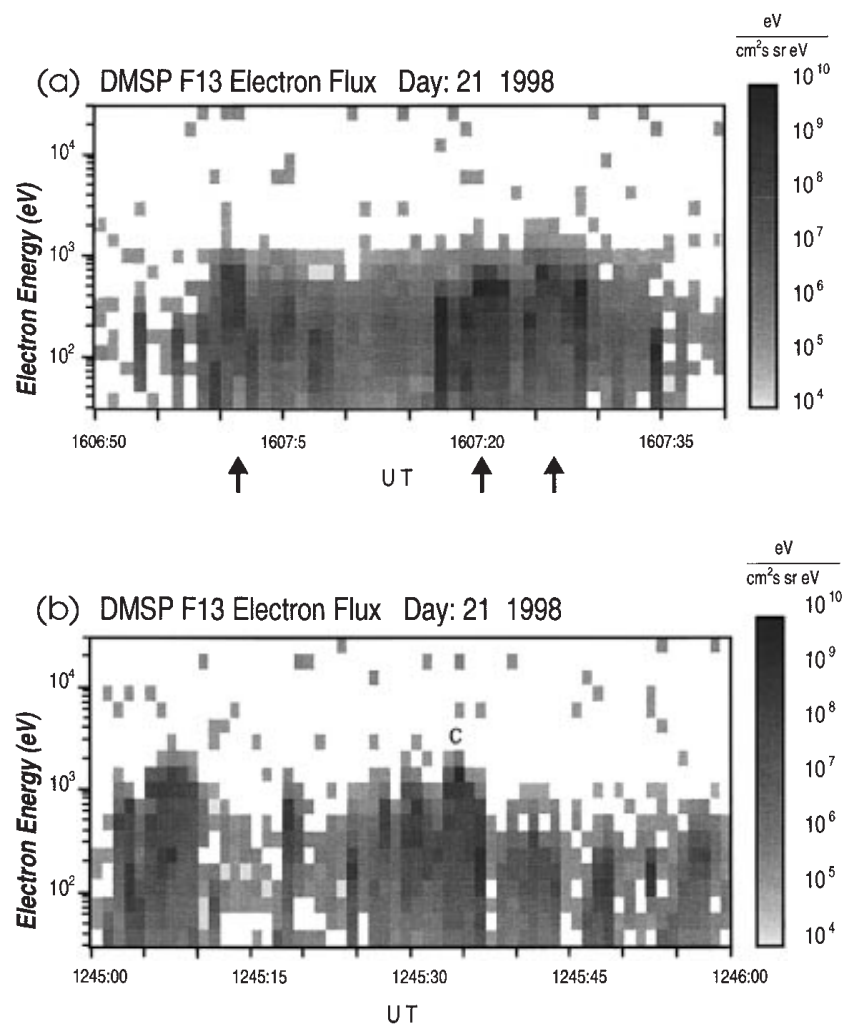

Fig. 9a, b. DMSP F13 differential electron energy flux a from 1606:50 to 1607:40 UT, and b from 1245 to 1246 UT on January 21, 1998

precipitation regions identified by the two arrows at 1607:21 and 1607:27 UT in Fig. 9a. The peak energies are about $500 \mathrm{eV}$. Those electrons produce the two partially resolved arcs seen in the zenith in Fig. 7. The $630.0 \mathrm{~nm}$ intensity reaches $1360 \mathrm{R}$ and that emission remains dominant as the arcs merge and slowly moved dawnward through the 15-min period shown. While the 
arcs persist their microstructures and intensities undergo many changes, as seen in the 427.8 and $557.7 \mathrm{~nm}$ emissions in Fig. 7.

2.1.3 January 21, 1237 UT. Figure 10 shows another (earlier) DMSP F13 satellite polar pass from 1237 to 1251 on January 21 with the electron precipitation patterns rather similar to the later pass described (Sect.
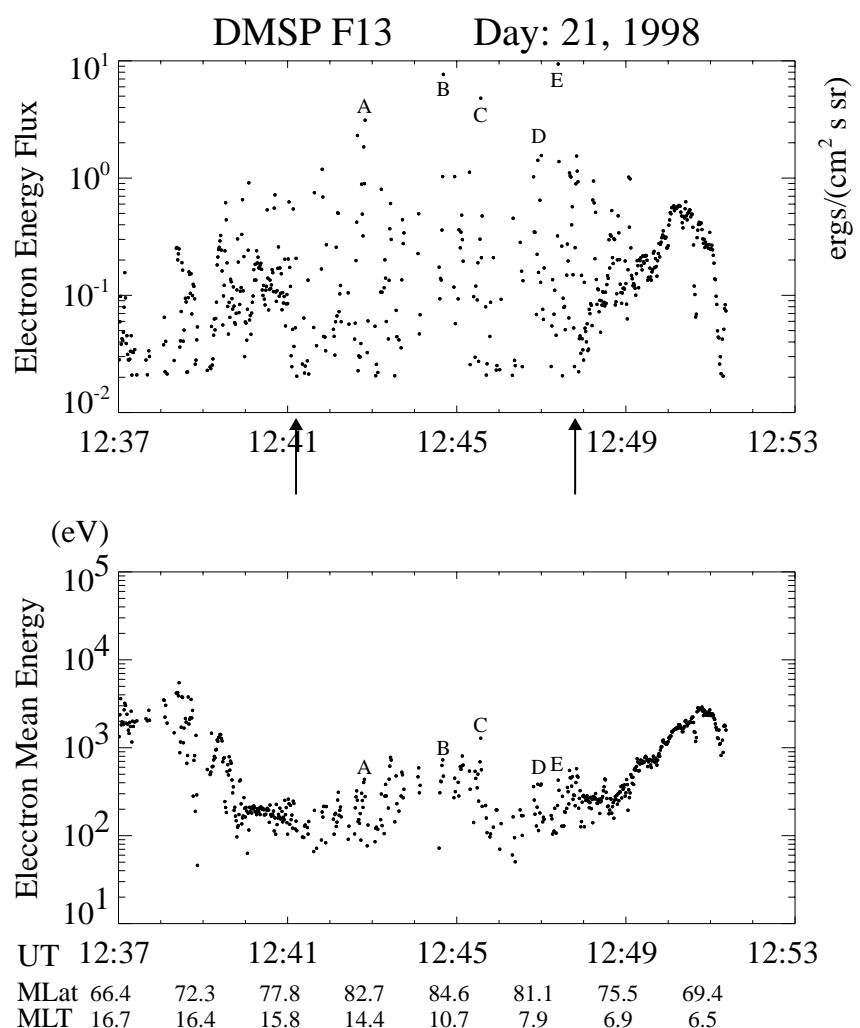

Fig. 10. Electron flux and energy plots similar to Fig. 8, but from a DMSP F13 pass from 1237 to 1253 UT on January 21, 1998
2.1.2). The polar cap dusk and dawn boundaries are about $79^{\circ} \mathrm{CGM}$ as identified by the two arrows in upper Fig. 10. There are many localized regions of electron precipitation. The major ones, with energy fluxes of $1 \mathrm{erg} /\left(\mathrm{cm}^{2} \mathrm{~s} \mathrm{sr}\right)$ or greater, are labelled A, B, C, D, and E from left to right as the satellite crosses the polar cap from dusk to dawn reaching a peak latitude of about $85^{\circ}$ CGM. The corresponding mean electron energies for the 5 events, as seen from the lower graph of Fig. 10 are 300, $700,1200,300$ and $400 \mathrm{eV}$, respectively. These are all above the mean precipitating electron energy of about $200 \mathrm{eV}$ in the surrounding regions. Event $\mathrm{C}(1200 \mathrm{eV})$ had an electron energy flux of $5 \mathrm{ergs} /\left(\mathrm{cm}^{2} \mathrm{~s} \mathrm{sr}\right)$ at 1245:35 UT with no detectable ion flux, in contrast with the other four events.

The Eureka MSP plots from 1241 to 1251 UT are shown in Fig. 11. They show all five of the events with event $\mathrm{A}$ in the dusk side, event $\mathrm{B}$ in zenith and events $\mathrm{C}$, $\mathrm{D}$ and $\mathrm{E}$ along the dawnside meridian. The optical intensities are quite variable in time. Of particular note is the $557.7 \mathrm{~nm}$ intensity of the arc just dawnward of zenith (event $\mathrm{C}$ in Fig. 10). The arc intensity increased from $200 \mathrm{R}$ to $1600 \mathrm{R}$ at $1245: 40$ then quickly decreased to $300 \mathrm{R}$. The corresponding $630.0 \mathrm{~nm}$ intensity changed relatively little. This suggests the energy of the precipitated electrons suddenly increased around 1245:40 UT, in agreement with the recorded $1200 \mathrm{eV}$ electron energy detected by DMSP F13 at that time. The F13 particle measurements were made at $84^{\circ}$ CGM, some distance dayward of the Eureka meridian scans of Fig. 11, but presumably crossing the same Sun-aligned polar arcs. While the arcs extend through the few hundred $\mathrm{km}$ separation between the Eureka meridian and the satellite crossing path the intensities are variable in time and along the arcs. This is illustrated in event B which has a recorded energy flux of $8 \mathrm{ergs} /\left(\mathrm{cm}^{2} \mathrm{~s} \mathrm{sr}\right)$ while across the Eureka meridian its optical intensity (Fig. 11) is quite low. A more detailed DMSP electron

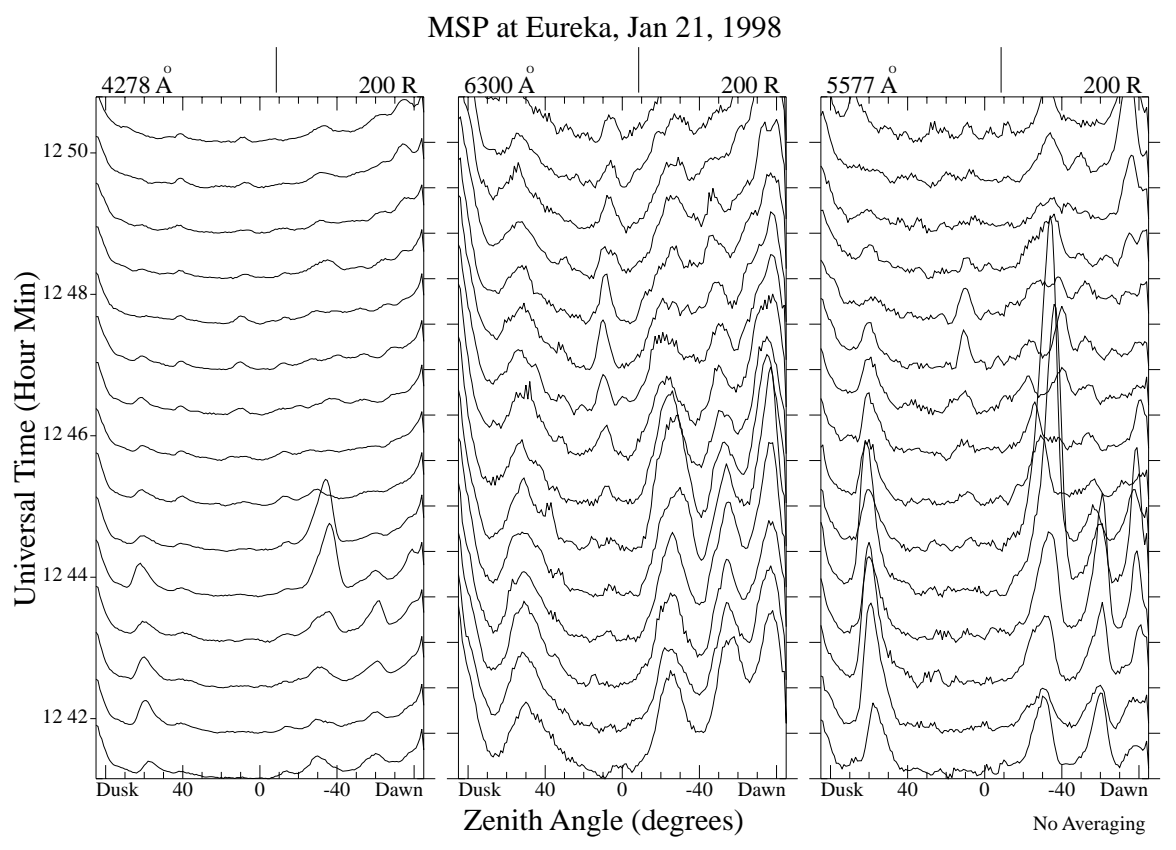

Fig. 11. Plots of MSP scans from 1241 to 1251 UT on January 21, 1998 
spectrum of event $\mathrm{C}$ is shown in Fig. 9b. The electron precipitation extends from 1245:24 to $1245: 37$, but a significant localized increase in the energy flux at $1200 \mathrm{eV}$ is seen at 1245:35 UT. The optical scans of Fig. 11 show that energization lasted only 1-2 min. Similar short-duration enhancements of $557.7 \mathrm{~nm}$ intensities can be seen in the other arcs at various times.

\subsection{Dynamics}

We have seen from the optical data in Figs. 7 and 11 that polar arcs are very dynamic. Their intensities change rapidly and they have variable lifetimes. The lack of detailed agreement between measured electron fluxes and optical intensities demonstrates that the arcs are not uniform along their length. The Sun-aligned arcs usually move in a direction perpendicular to their length. We will examine these motions in relation to IMF $B_{y}$ changes, and look at polar ionospheric convection as a function of $B_{y}$ and $B_{z}$ changes.

2.2.1 Motion of polar arcs and IMF $B_{y}$. The motion of polar arcs in a dawn-dusk direction appears to be controlled by the IMF $B_{y}$ polarity. A few examples from Eureka observations on January 19, 1998 illustrate this. Figure 12 shows the MSP scan plots of 630.0 and $557.7 \mathrm{~nm}$ emissions from 0300 to 0800 UT. Polar arcs first appear in the dawn side and then move in the duskward direction across the central polar region over the 5-h period. Note from Fig. 2 that IMF $B_{y}$ was positive (up to $10 \mathrm{nT}$ ) between 0000 and $1030 \mathrm{UT}$.

Figure 13 shows another example from 1530 to 1630 UT. Here the polar arcs moved small amounts alternately in duskward and dawnward directions for an hour, but remained relatively stable. The IMF $B_{y}$ was near zero and oscillating between 1500 and 1540 UT (see Fig. 2)

Figure 14 shows an example from 2220 to 2350 UT. The MSP plots show that polar arcs were first initiated in the dusk side and moved toward dawn side across the pole over a period of one hour. The corresponding IMF $B_{y}$ was quite strongly negative during the period (see Fig. 2).

More detailed studies of all the polar arcs during the 4-day period show that when IMF $B_{z}$ was stable (northward), a sudden change in IMF $B_{y}$ polarity from positive to negative produced new polar arcs in the dusk side with motion in a dawnward direction. Similarly, when $B_{y}$ suddenly changed from negative to positive, arcs appeared in the dawnside with motion duskward. The time delays between the sudden changes in $B_{y}$ and appearance of new arcs were around 20-60 min, taking into acount the propagation time from the WIND satellite to the magnetopause.

2.2.2 Polar ionospheric convection and IMF $B_{z}$. A FabryPerot Interferometer was operated at Eureka during 1997-98, measuring neutral F-region wind velocities from $630.0 \mathrm{~nm}$ emissions. Figure 15 shows the wind velocities measured over the 4-day period from January 19 to 22,1998 . Winds over the magnetic pole are generally antisunward, so the wind vectors shown are all relative to the Sun-Earth direction. When the IMF $B_{z}$ was northward (most of the 4-day period) the velocity was from 100 to $150 \mathrm{~m} / \mathrm{s}$. The velocity is seen to increase whenever $B_{z}$ goes consistently negative, as from 1300 to 2300 UT on January 20 (see Fig. 2). The F-region wind reached a peak of $500 \mathrm{~m} / \mathrm{s}$ during that interval. It gradually dropped to $150 \mathrm{~m} / \mathrm{s}$ after $B_{z}$ turned northward.

One may also note that the winds are inclined toward the duskward direction when $B_{y}$ is positive and toward

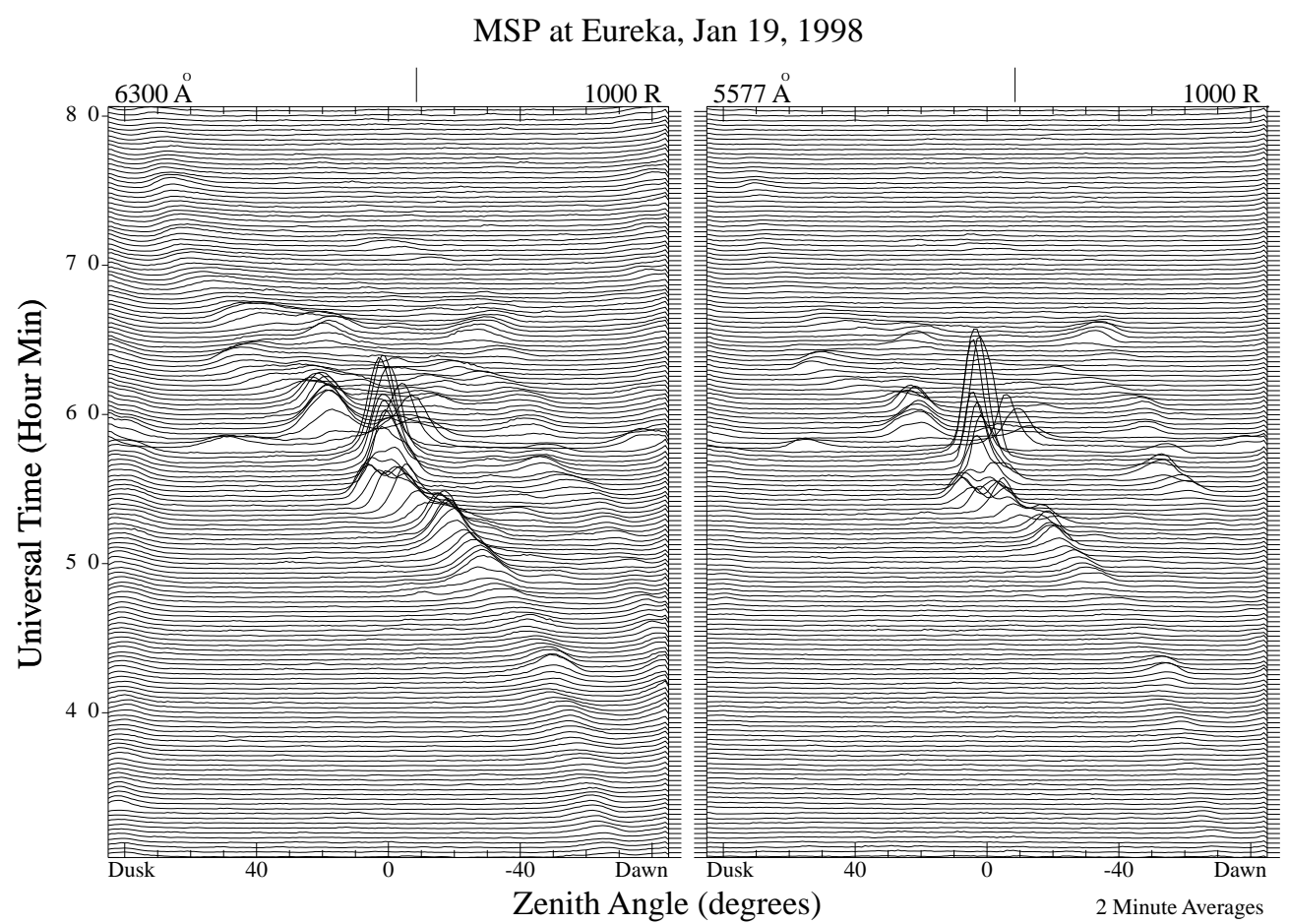

Fig. 12. Plots of MSP scans from 0300 to 0800 UT on January 19, 1998. The data are each averaged for 2 min. Vertical bars at the top denote $1000 \mathrm{R}$ 


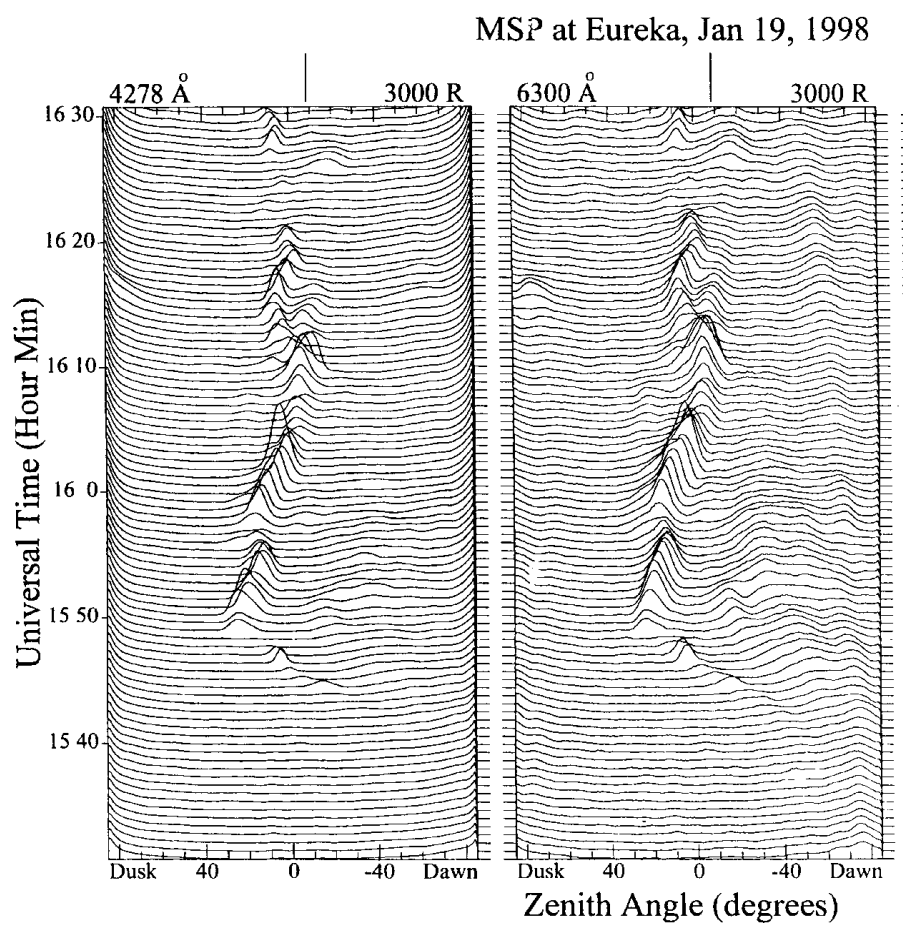

MSP at Eureka, Jan 19, 1998

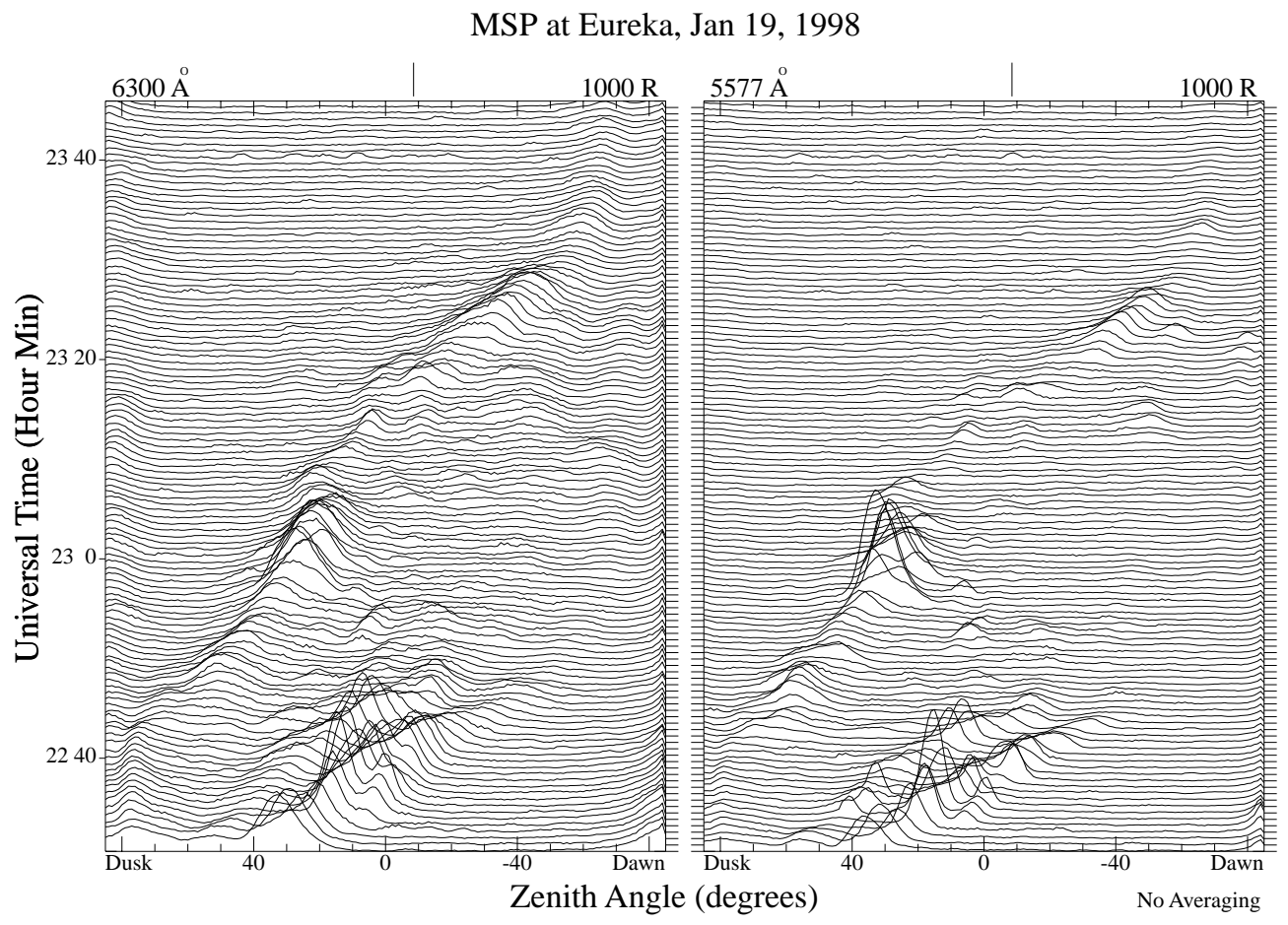

Fig. 13. Plots of MSP scans from 1530 to 1630 UT on January 19, 1998. Vertical bars at the top denote $3000 \mathrm{R}$
Fig. 14. Plots of MSP scans from 2220 to 2350 UT on January 19,1998 the dawnward direction when $B_{y}$ is negative. Thus the convection is strongly controlled by the polarity of both the IMF $B_{z}$ and $B_{y}$.

\section{Discussion}

We have examined the solar wind effects on the polar ionosphere during a 4-day period in January, 1998 when the solar wind IMF was quite strong and highly variable. The ionospheric parameters studied have been polar auroral arcs and neutral F-region winds and their dynamical features in response to solar wind IMF changes. The availability of continuous ground-based optical data from Eureka and DMSP F13 overpasses of the auroral oval and polar region has made possible a rather detailed study of the polar cap and particle precipitation for that 4-day period.

For some intervals, as during January 20 when the IMF $B_{z}$ was about $-8 \mathrm{nT}$, the whole polar region above 
Sunward

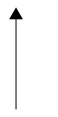

\section{FPI Sun-Aligned Winds}

Eureka $6300 \AA^{\circ}$

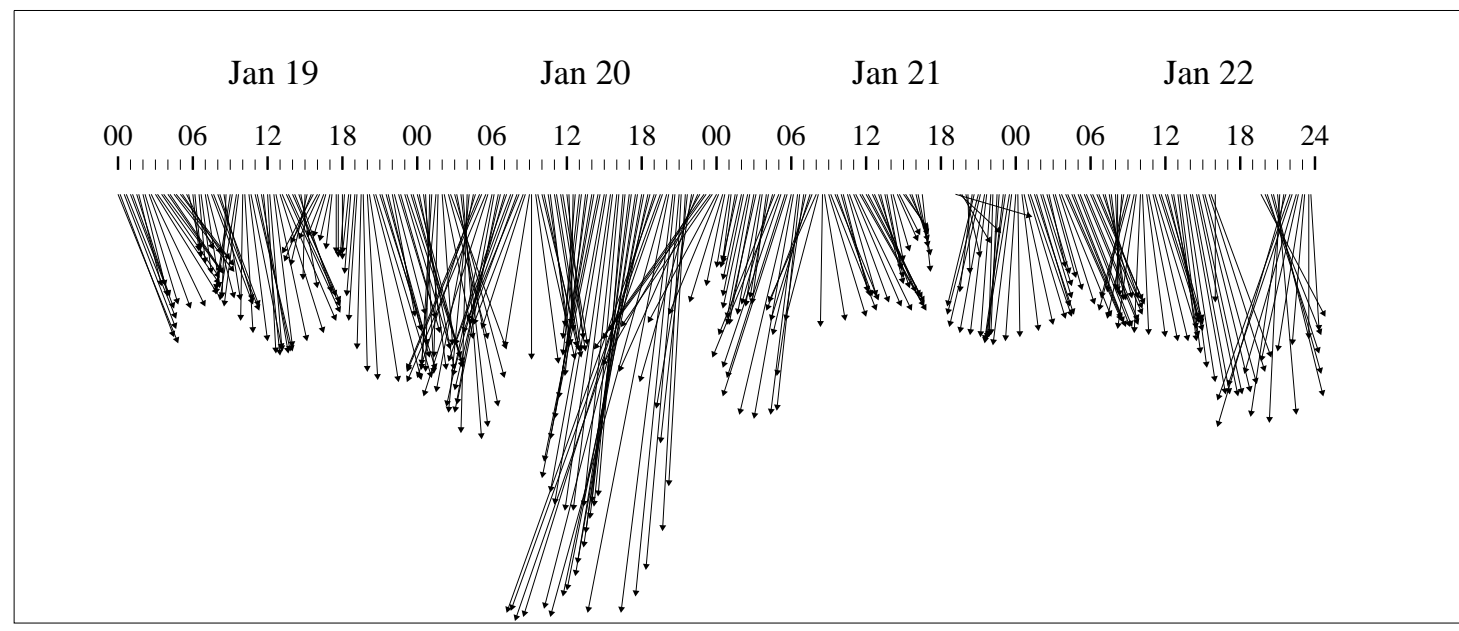

$100 \mathrm{~m} / \mathrm{s}$

Jan 19-22 / 98

Fig. 15. Eureka FPI $(630.0 \mathrm{~nm})$ F-region neutral wind vectors recorded over a 4-day period from January 19 to 22 , 1998 . They are plotted relative to the Sun-Earth direction with Sunward vertically upward. The velocity scale is illustrated by a $100 \mathrm{~m} / \mathrm{s} v e c t o r$ at the $b o t t o m$

$79^{\circ}$ was devoid of activity, except for a low level of electron precipitation of $150 \mathrm{eV}$ average energy identified as polar rain. Figure 3 shows the electron influx during one such DMSP pass. There was no detectable ion influx. For most of the remainder of the January 4-day period the IMF $B_{z}$ was positive and there were frequent auroral Sun-aligned arcs in the polar region. Some of these have been shown here.

\subsection{Characteristics of polar arcs}

The combined particle and optical data have been complementory; while the DMSP particle data provide good spatial resolution and details of electron spectral influx, the optical data provide the temporal and spatial evolution of the auroral arcs within the polar region. The many arcs detected were excited mainly by 200 $500 \mathrm{eV}$ electrons and their $630.0 \mathrm{~nm}$ emission was stronger than $557.7 \mathrm{~nm}$ usually. There were however several observations of transient $557.7 \mathrm{~nm}$ emission enhancements (see Figs. 6, 7, 11) which indicated energization of the electron influx. The F13 crossing on January 21 (Fig. 10) recorded mean electron energies of 700 and $1200 \mathrm{eV}$ over two arcs. The 630.0/557.7 intensity ratios, measured from below, established that those high energies occurred only briefly. Detailed electron spectra showed some inverted-V structure over several of the arcs with centre energies somewhat higher than at edges. In general the average electron energies (see Figs. 4, 8) across the polar region were rather similar to those on the poleward sides of the auroral oval. Polar arc intensities were quite variable, from instrument threshold (about $10 \mathrm{R}$ ) up to several kR (as in Fig. 13). On average they were only $\sim 300 \mathrm{R}$, and so mostly subvisual. Each arc was identifiable from either the electron precipitation or the optical emission, with similar location and cross-section, but the intensities often differed. This was indicative of variabilities along the sun-aligned arcs reviewed. Arc widths were typically only $10-20 \mathrm{~km}$, but the electron spectra sometimes showed narrower filamentary structure (as in Fig. 9). Lifetimes of the polar arcs ranged from only 1-2 min (for weaker ones) to several hours.

Ion precipitation accompanied the electron precipitation, for most of the events shown here (in Figs. 4, 8 and 10), but the total ion energy fluxes were on average only a few percent of the energy influx from the electrons. There was no means of inferring the particle source region from the ion spectra. The DMSP satellite traversed localized narrow regions of precipitation with no identificable temporal variations (or dispersion). The particle fluxes associated with these polar arcs had rather similar characteristics to the precipitation in the poleward portions of the auroral oval suggesting they come from the plasma sheet boundary layer.

Two of the arcs observed (event A of Fig. 8 and event $\mathrm{C}$ of Fig. 10) had no detectable ion influx. They were located at $83-85^{\circ} \mathrm{CGM}$ and during those DMSP passes the whole central polar region was devoid of ion flux. The mean electron energies from those arcs $(500 \mathrm{eV}$ and $1200 \mathrm{eV}$ ) were somewhat higher than those for the arcs with ion precipitation. In other respects the two arcs 
appeared no different from the other arcs already described. Shinohara and Kokubun (1996) have identified two types of polar showers from analysis of many DMSP polar passes with the IMF $B_{z}$ northward, those without ion fluxes and believed to originate in the solar wind, and those with ion fluxes considered to come from the boundary plasma sheet along closed field lines. They found also that the polar showers without ion influx tended to have somewhat higher average electron energies.

One could suggest similarly that the particles generating polar arcs can come from either of two sources, solar wind electron influx via the magnetosheath and the lobe regions in some cases, and the plasma sheet boundary layer more commonly. This topic needs to be addressed further with detailed inspection of electron and ion spectra from many satellite polar passes with IMF $B_{z}$ northward.

\subsection{Polar arc location, motion and IMF $B_{y}$}

The continuity of observations of many polar arcs over Eureka during the 4-day period allowed us to trace the initial location and motion of polar arcs in association with IMF conditions. It was found that:

1. When the IMF $B_{y}$ is positive, the polar arcs occur in the dawn side and move duskward.

2. When $B_{y}$ is negative, polar arcs occur in the dusk side and move dawnward.

3. When $B_{y}$ is small or around zero, the polar arcs are stable and stay in the central polar region.

4. Sudden changes of IMF $B_{y}$, from positive to negative or from negative to positive can initiate new polar arcs in dusk side or dawn side, respectively.

All 10 major polar arcs viewed in the 4-day period appeared following large transitions in $B_{y}$. The time delays could not be determined with precision, since the arcs most commonly appeared from the flank regions, but they were about 20-60 min in general.

These results extend the earlier observations by Valladares et al. (1994) that polar arcs move dawnward (duskward) when IMF $B_{y}$ is negative (positive). Our study shows also that a sudden polarity change of IMF $B_{y}$ can initiate new polar arcs.

\subsection{Polar ionospheric convection and IMF $B_{z}$}

The neutral winds in the F-region monitored by the FPI are largely controlled by ion convection across the polar region. So the neutral wind speed responds to changes in ion convection speed. The high/low polar ionospheric F-region convection speeds up under southward/northward IMF $B_{z}$ inferred from the FPI winds shown in Fig. 15 support earlier results obtained by Niciejewski et al. (1994). As the ion convection is driven by $\mathbf{E} \times \mathbf{B}$ drift, the high ion convection speed can be well explained by the high dawn-to-dusk electric field under southward IMF $B_{z}$. Thus observations of the polar F- region neutral winds provide another way to monitor the IMF $B_{z}$ polarity.

\section{Summary and conclusions}

This case study of polar ionospheric responses to changes in the solar wind IMF has emphasized several things about polar arcs and their excitation, as well as IMF control over polar convection and F-region winds. Regarding polar auroral arcs:

1. They are excited usually by $200-500 \mathrm{eV}$ electrons, with $630.0 \mathrm{~nm}$ the major emission. Only occasionally is there indication of acceleration (up to $\sim 1 \mathrm{keV}$ ); acceleration when observed appears transient).

2 . They are on average only about $10-20 \mathrm{~km}$ in width.

3 . They are usually initiated in the duskside/dawnside and move dawnward (duskward) when IMF $B_{y}$ is negative (positive). Sudden changes in IMF $B_{y}$ can result in the formation of new polar arcs.

4. There is evidence from the combined electron and ion data that the source region is the plasma sheet boundary layer in most cases. The absence of ion fluxes in a few cases $\left(\frac{2}{11}\right)$ suggests a magnetosheath source of electrons for some polar arcs.

Anti-sunward F-region wind speed is low when the IMF $B_{z}$ is northward and the convection is enhanced (up to $\sim 500 \mathrm{~m} / \mathrm{s}$ ) when IMF $B_{z}$ is southward. Its direction is influenced by the IMF $B_{y}$ sign and magnitude.

Acknowledgements. This work was supported by an NSERC operating grant. The logistic support of the Atmospheric Environment Service staff at Eureka is much appreciated. We are grateful to R.P. Lepping and K. Ogilvie for WIND solar wind IMF and particle data.

Topical Editor M. Lester thanks D. J. Knipp and another referee for their help in evaluating this paper.

\section{References}

Baker, D. N., A. Nishida, T. Mukai, T. Yamamoto, Y. Saito, Y. Matsuno, S. Kokubun, and T. I. Pulkkinen, Observations of bidirectional electrons in the distant tail lobes: GEOTAIL results, Geophys. Res. Lett., 24, 959-962, 1997.

Carlson, H. C., Dynamics of the quiet polar cap, J. Geomagn. Geoelectr., 42, 697-710, 1990.

Davis, T. N., The morphology of the polar aurora, J. Geophys. Res., 65, 3497, 1960.

Fairfield, D. H., Structure of the geomagnetic tail, in Magnetotail physics, Ed. A. T. Y. Lui pp 23-33, Johns Hopkins University Press, Baltimore 1987.

Fairfield, D. H., R. P. Lepping, L. A. Frank, K. L. Ackerson, W. R. Paterson, S. Kokubun, T. Yamamoto, K. Tsuruda, and M. Nakamura, Geotail observations of an unusual magnetotail under very northward IMF conditions, J. Geomagn. Geoelect., 48, 473-487, 1996.

Frank, L. A., J. D. Craven, J. L. Burch, and J. D. Winningham, Polar views of the Earth's aurora with Dynamic Explorer, Geophys. Res. Lett., 9, 1001, 1982.

Gosling, J. T., M. F. Thomsen, G. Le, and C. T. Russell, Observations of magnetic reconnection at the lobe magnetopause, J. Geophys. Res., 101, 24 765-24 773, 1996. 
Heelis, R. A., The effect of interplanetary magnetic field orientation on dayside high-latitude ionospheric convection, J. Geophys. Res., 89, 2873-2888, 1984.

Huang, K., D. J. McEwen, and I. Oznovich, Analysis of a polar auroral arc observed from Eureka $\left(89^{\circ} \mathrm{N}\right)$ and by DMSP satellites on December 14, 1990, J. Geophys. Res., 99, 21 353-21 359, 1994.

McEwen, D. J., and K. Huang, The polar onset and development of the November 8 and 9, 1991, global red aurora, J. Geophys. Res., 100, 19 585-19 594, 1995.

McEwen, D. J., and D. P. Harris, Observations of F layer patches and their convection over the north magnetic pole, Adv. Space Res., 16, 69-72, 1995.

McEwen, D. J., and D. P. Harris, Occurrence pattern of F-layer patches over the north magnetic pole, Radio Sci., 31, 619-628, 1996.

McEwen, D. J., D. P. Harris, J. W. MacDougall, and I. F. Grant, Drifting F-layer patches over the magnetic pole, J. Geomagn. Geoelectr., 47, 527-537, 1995.

Murphree, J. S., S. Ismail, L. L. Cogger, D. D. Wallis, G. G. Shepherd, R. Link, and D. M. Klumpar, Characteristics of optical emissions and particle precipitations in polar cap arcs, Planet. Space Sci., 31, 161-172, 1983.

Niciejewski, R. J., T. L. Killeen, and Y. Won, Observations of neutral winds in the polar cap during northward IMF, J. Atmos. Terr. Phys., 56, 285, 1994.

Oznovich, I., and D. J. McEwen, Auroral emissions at the north magnetic pole - a February 17, 1993 case study, J. Geomag. Geoelectr., 46, 861, 1994.

Rich, F. J., D. A. Hardy, R. H. Redus, and M. S. Gussenhoven, Northward IMF and patterns of high-latitude precipitation and field-aligned currents: the February 1986 storm, J. Geophys. Res., 95, 7893, 1990.

Shinohara, K., and S. Kokubun, Statistical properties of particle precipitation in the polar cap during intervals of northward interplanetary magnetic field, J. Geophys. Res., 101, 69-82, 1996.

Valladares, C. E., and H. C. Carlson, Jr., The electrodynamic, thermal, and energetic character of intense sun-aligned arcs in the polar cap, J. Geophys. Res., 96, 1379, 1991.

Valladares, C. E., H. C. Carlson, and K. Fukui, Interplanetary magnetic field dependence of stable Sun-aligned arcs in the polar cap, J. Geophys. Res., 99, 6247-6272, 1994. 